Hispania Sacra, Medievalia hispanica, 58 117, enero-junio 2006, 9-35, ISSN: 0018-215-X

\title{
EL CAMBIO DE RITO EN CASTILLA: SU ITER HISTORIOGRÁFICO EN LOS SIGLOS XII Y XIII*
}

\author{
POR
}

\author{
JuAn Pablo Rubio SAdia, OSB
}

Abadía de la Santa Cruz del Valle de los Caídos

\begin{abstract}
RESUMEN
Las vicisitudes que acompañaron al cambio de rito en el reino de Castilla y León a finales del siglo XI tuvieron diversas e interesantes interpretaciones en las crónicas y cronicones de los dos siglos inmediatamente posteriores. En este artículo se analiza el itinerario historiográfico de la cuestión ritual, atendiendo a una doble perspectiva: la sincrónica, que estudia el contexto, los datos y la intencionalidad de cada uno de los autores; y la diacrónica, que se fija en el proceso de transmisión literaria. El estudio nos permite adquirir una perspectiva clara de la receptio de un importante acontecimiento, distinguiendo los elementos históricos, legendarios y ficticios.
\end{abstract}

PALABRAS CLAVE: rito romano, rito hispano, cambio de rito, crónica, cronicón, reino de Castilla y León, Alfonso VI, Burgos.

\section{ABSTRACT}

The circumstances which accompanied to the change of rite in the kingdom of León-Castile at the end of 11 th century had diverse and interesting interpretations in the chronicles and Chronicon books of the two immediately following centuries. In this article, the historiographic route of the ritual question

\footnotetext{
* Siglas empleadas: $A C=$ Annales Compostellani, BRAH=Boletín de la Real Academia de la Historia, $C B=$ Chronicon Burgense, $C C=$ Chronicon de Cardeña, CCCM=Corpus Christianorum. Continuatio Mediaevalis, $C L M R=$ Clásicos Latinos Medievales y Renacentistas $(\mathrm{Akal}), C M=$ Chronicon mundi, $C N=$ Chronica Naierensis, $C P=$ Crónica del obispo don Pelayo de Oviedo, $C S_{1}=$ Crónica anónima de Sahagún (siglo XII), $\mathrm{CS}_{2}=$ Crónica anónima de Sahagún (continuación del siglo XIII), DHEE = Diccionario de Historia Eclesiástica de España, ES= España Sagrada, HC= Historia Compostellana, $R H=$ De rebus Hispaniae.
} 


\begin{abstract}
is analysed, looking to a double perspective: the synchronic one, that studies the context, the data and the author's purpose; and the diachronic one, that considers the process of literary transmission. This study let us to have a clear perspective of the receptio of an important event, discerning the historical, legendary and fictitious elements.
\end{abstract}

KEY WORDS: Roman rite, Old Spanish rite, change of rite, chronicle, Chronicon, kingdom of León-Castile, Alfonso VI, Burgos.

\title{
INTRODUCCIÓN
}

Entre los acontecimientos que marcaron más sensiblemente la vida del reino de Castilla y León durante el último tercio del siglo XI se halla sin duda la supresión de la liturgia hispánica (también llamada aunque impropiamente, mozárabe) y la implantación en su lugar de la liturgia romana. No es necesario enfatizar la importancia de este interesante y complejo asunto humano, cultural y eclesial, abordado ya desde diversos puntos de vista por liturgistas e historiadores. Sabemos que en él confluyeron una rica variedad de factores religiosos, políticos y culturales, que generó resistencias y tensiones, que intensificó las relaciones de la Península con el Mediodía francés y con Roma y que, al mismo tiempo, ocasionó un fenómeno, aún poco estudiado, de asimilación de la nueva liturgia y una intensísima importación y producción de códices para el culto.

La imposición de la liturgia romana tuvo su eco en la historiografía medieval tanto latina como romance. Diversos cronistas dejaron constancia en sus obras de lo acontecido entre 1076 y 1080 en los territorios gobernados por Alfonso VI (1065-1109). Es precisamente este aspecto el que me propongo estudiar desde una doble vertiente. Por un lado, la recepción que el cambio de rito tuvo en las crónicas y cronicones de los siglos XII y XIII. Con una perspectiva sincrónica pretendo examinar los datos recogidos en las fuentes, su contexto, su intencionalidad e interpretación. Por otro lado, voy a analizar el proceso de transmisión literaria de unas fuentes a otras (perspectiva diacrónica), es decir, el iter historiográfico del cambio ritual a lo largo de los dos siglos inmediatamente posteriores. El límite cronológico establecido para nuestro trabajo no es arbitrario. Es bien conocido que en el siglo XIII se produjo un cambio significativo en la historiografía medieval, reflejado principalmente en la obra histórica del rey Alfonso X el Sabio (1252-1284) escrita ya en lengua romance. 


\section{LAS CRÓNICAS DEL SIGLO XII}

\subsection{La Historia Compostelana}

Nuestro itinerario historiográfico a propósito del cambio de liturgia en Castilla y León tiene su primera etapa, aunque ciertamente efímera, en la $H C$, «joya de la historiografía latina peninsular» ${ }^{1}$, escrita a principios del siglo XII y estrechamente vinculada a la figura de don Diego Gelmírez (1110-1140), primer arzobispo de Compostela. Se trata fundamentalmente de una narración cuyo propósito es recordar y glorificar los hechos del prelado, por lo que su información sobre obispos o sucesos anteriores resulta muy escasa. No obstante, contiene una brevísima alusión al cambio de liturgia en los capítulos introductorios del libro I, que fueron añadidos con posterioridad para dar la debida proyección histórica al episcopado de don Gelmírez y a su posterior arzobispado ${ }^{2}$. Leamos el texto en cuestión:

$H C$, I, $2.12^{3}$ :

Porro in eadem cathedra Didacus Pelaiz a domino rege Sanctio sublimatus est. In hoc tempore apud Hispanos lex Toletana obliterata est et lex Romana recepta.
Luego fue elevado a la misma cátedra Diego Peláez por el rey don Sancho. En este tiempo el rito toledano fue olvidado y fue aceptado el rito romano.

La referencia está inserta en la noticia dada acerca del obispo don Diego Peláez. Se trata de la mera constatación del paso de un rito a otro (del toledano o hispánico al romano). La ubicación temporal tampoco parece interesar mucho. Tan sólo se dice, después de aludir a don Diego, In hoc tempore, es decir, durante los años de su gobierno que transcurrieron entre cerca de 1071 y 1088. Esta alusión recuerda, como veremos, el estilo de algunos cronicones del siglo XIII. El motivo del nulo interés que suscita el cambio ritual podría buscarse en la autoría de esta parte de la HC. Si sostenemos, de acuerdo con F. López Alsina, que $H C$ I, 1-3 fue redactada por uno de los autores gallegos, antes que por el francés Giraldo de Beauvais ${ }^{4}$, podemos suponer que el autor no viera con buenos ojos la supresión de la liturgia autóctona. Giraldo, en cambio, es presumible que hubiese sido menos lacónico al respecto, dado su origen francés y su discurso filocluniacense ${ }^{5}$. Al fin y al cabo, la Orden de Cluny había sido la gran

\footnotetext{
1 C. SÁnchez Albornoz, Españoles ante la historia, Buenos Aires, 1977 (3. a ed.), 76.

2 Historia Compostelana, Introducción, traducción, notas e índices de E. FALQUE ReY, CLMR 3, Madrid, 1994, 8.

${ }^{3}$ Historia Compostellana, cura et studio E. FAlQUe Rey, CCCM 70, Turnhout, 1988, 15; la traducción en: FAlQue Rey, CLMR 3, 77. El texto latino lo encontramos también en: H. FLóReZ (ed.), Historia Compostelana, ES XX, Madrid, 1791 (2. ${ }^{\mathrm{a}}$ ed.), 16.

${ }^{4}$ Falque Rey, CLMR 3, 14.

${ }^{5}$ Un ejemplo de su veneración hacia Cluny lo tenemos en $H C$, II, 14, 2, donde escribe: «A decir
} 
aliada de Alfonso VI a favor de la imposición de la Lex Romana en la Península. No obstante, me inclino a pensar que, incluso si el autor fue Giraldo, el verdadero motivo radica simplemente en que, para los fines de la obra, no interesaba en absoluto vincular un hecho tan relevante, como en realidad era el cambio de liturgia, con el episcopado de don Peláez, obispo que en la $H C$ recibe un juicio más bien negativo ${ }^{6}$.

Esta noticia se complementa con otra ciertamente imprecisa, pero que no debemos dejar de lado:

$H C$, II, $3.1^{7}$ :

Fuit namque in ecclesiasticis et in secularibus negotiis uir perspicacissimi ingenii; et, quoniam ecclesia beati Iacobi rudis et indisciplinata erat temporibus illis, applicuit animum, ut consuetudines ecclesiarum Francie ibi plantaret. Quod nimis laboriosum fuit ei $[\ldots]$
Fue [don Gelmírez] en los asuntos eclesiásticos y en los seculares hombre de ingenio muy perspicaz y puesto que la Iglesia de Santiago era en aquellos tiempos ruda y sin disciplina, se dedicó a trasplantar allí las costumbres de las iglesias de Francia. Esto fue para él muy laborioso [...]

El profesor Pedro Romano Rocha considera que esta afirmación afecta también al campo litúrgico: «Fijándonos en Francia, no olvidemos que, antes de Gelmírez, fue obispo de Santiago un cluniacense francés, Dalmacio. Pensamos también en los clérigos que eran enviados al extranjero a estudiar y pensamos además en el movimiento espiritual que traía tantos cristianos en peregrinación al santuario del Apóstol. El camino de Santiago no dejó huellas solamente en el campo del arte y de la literatura. Creo que también dejó huella en la liturgia» ${ }^{8}$. Por todo ello, creo que esta alusión nos pone en contacto con la introducción de facto del rito romano en la Iglesia compostelana, es decir, con su lenta y laboriosa (Quod nimis laboriosum fuit ei) asimilación vital ${ }^{9}$.

verdad, el monasterio de Cluny aventaja a todas la iglesias de Francia y destaca por encima de ellas en santidad y caridad».

6 Sobre el prelado podemos leer el siguiente párrafo que sigue a la referencia sobre la liturgia: «El mencionado Diego floreció en esta vida presente durante mucho tiempo en nobleza y generosidad. Pero vivió hasta tal punto entregado a las preocupaciones del mundo que no adaptó, como era su deber, su vida interior a la norma del hábito eclesiástico. Por lo que, apresado por el rey don Alfonso, según lo había merecido, permaneció encadenado durante quince años».

${ }^{7}$ FALQUe Rey, CCCM 70, 222; la traducción en: FALQUe Rey, CLMR 3, 300.

8 P.-R- RochA, «La liturgia de Compostela a fines del siglo XII», en Simposio Internacional sobre «O Pórtico da Gloria e o Arte do seu tempo», Santiago de Compostela, 3-8 Octubro de 1988.

${ }^{9}$ Hay que reconocer desgraciadamente con Manuel Cecilio Díaz que «nos faltan estudios sobre esta profunda transformación litúrgica, que afectó no poco a las costumbres cristianas del pueblo. En general se pasa por encima de este suceso sin ahondar debidamente en él, a pesar de que sabemos que la reacción debió ser fuerte y duradera; en ciertos campos, como el de la liturgia de los sacramentos, la pervivencia de los ritos antiguos fue notable»; M. CECILIo DíAZ, «La diócesis de Iria-Compostela hasta 1100», en Historia de las diócesis españolas, 14: Santiago de Compostela y Tuy-Vigo, Madrid, 2002, 35.

Hispania Sacra, Medievalia hispanica, 58

117, enero-junio 2006, 9-35, ISSN: 0018-215-X 


\subsection{La crónica del obispo don Pelayo de Oviedo}

Mayor relevancia para nuestro propósito tiene la crónica del obispo don Pelayo de Oviedo ${ }^{10}$, un poco posterior a la $H C$ y muy influida por ella. Compuesta a principios del siglo XII con el propósito de enaltecer el solio ovetense, es una de las crónicas más próximas al hecho histórico que nos ocupa. Además su autor, que vivió en la segunda mitad del siglo XI y primera del XII, fue contemporáneo de una parte de los sucesos que narra ${ }^{11}$. El profesor Bernard F. Reilly está de acuerdo en señalar que es ésta la fuente más digna de crédito acerca del reinado de Alfonso VI, poniendo de relieve que don Pelayo fue cortesano de este monarca ${ }^{12}$. Precisamente el relato del reinado alfonsino constituye la parte más sustanciosa de la crónica, «especialmente por sus noticias de su riguroso gobierno del monarca y de la paz interior que de ellos fue corolario» ${ }^{13}$. En esta sección encontramos la alusión al cambio de rito:

\begin{abstract}
$C P,[\text { Adefonsus } \mathrm{VI}]^{14}$ :
Tunc Adefonsus rex uelociter Romam nuntios misit ad Papam Aldebrandum cognomento Septimus Gregorius; ideo hoc fecit, quia romanum misterium habere uoluit in omni regno suo. Memoratus itaque Papa Cardinalem suum Ricardum, Abbatem Marsiliensem, in Hispana transmisit. Qui apud Burgensem urbem Concilium celebrauit confirmauitque romanum misterium in omni regno regis Adefonsi Era MCXIIII.
\end{abstract}

Entonces el rey Alfonso envió rápidamente legados a Roma al papa Hildebrando, llamado Gregorio VII. Hizo, por tanto, esto porque quiso tener el rito romano en todo su reino. Así pues, el recordado papa envió a España a su cardenal Ricardo, abad de Marsella. El cual celebró un concilio en la ciudad de Burgos y confirmó el rito romano en todo el reino del rey Alfonso. En la era de 1076.

Esta noticia es ciertamente breve, pero contiene un conjunto de datos de suma importancia. Su inclusión está casi al inicio de la sección dedicada al reinado de Alfonso VI. En concreto, sigue a la narración del apoderamiento de los reinos de sus hermanos Sancho II el Fuerte (asesinado en el asedio de Zamora en 1072) y García (encarcelado en el castillo de Luna hasta su muerte en 1090). Notemos, pues, que en el corpus de información de don Pelayo sobre el período alfonsino el suceso del cambio de liturgia ocupa un puesto destacado ${ }^{15}$. En pri-

10 Para esta obra sigo la edición de B. SÁnchez Alonso: Crónica del obispo don Pelayo, Madrid, 1924. La crónica se encuentra igualmente en: H. FLóREZ (ed.), Chronicon de Don Pelayo, ES XIV, Madrid, 1786, 480-490.

11 SÁnChEZ Alonso, 41.

12 B. F. ReILLy, El reino de León y Castilla bajo el rey Alfonso VI (1065-1109), Toledo, 1989, 13.

13 SÁnCHEZ Alonso, 48.

14 SÁNCHez Alonso, 80.

15 Es curioso comprobar que en el ms. B, el más antiguo que se posee de texto completo (BN, 
mer lugar, llama la atención el hecho de que en la $C P$ la iniciativa de la introducción de la liturgia romana es atribuida a Alfonso VI y no al papa Gregorio VII (1073-1085) ${ }^{16}$. En efecto, el texto pelagiano dice: Adefonsus rex uelociter Romam nuncios misit ad Papam Aldebrandum y el motivo de tal iniciativa viene expresado a continuación: hoc fecit, quia romanum misterium habere uoluit in omni regno suo. El sujeto es siempre el monarca castellano. No hay mención alguna de presión por parte del pontífice romano, que se limita a confirmar la iniciativa real por medio de un legado. Este dato historiográfico está en consonancia con el espíritu europeísta de Alfonso, para quien la adopción del rito romano podía ser un factor de acercamiento y apertura hacia los demás reinos de la Cristiandad, al igual que la entrada de los monjes cluniacenses y de los peregrinos que recorrían el camino compostelano.

El texto del Ovetense recoge otros datos: la respuesta del papa, que envía al cardenal Ricardo como legado pontificio, y la celebración de un concilio en Burgos con fecha de 1076, en el cual el legado confirma el rito romano. Sin duda la cuestión cronológica es la más interesante y la más controvertida. Hay que resaltar que don Pelayo, sin conocer $C S_{1}$ (también de principios del siglo $\mathrm{XII})$, coincide con ella en la misma fecha. Aunque la $C P$ asocia erróneamente el suceso de 1076 con la segunda legación del cardenal Ricardo, ya por entonces abad de Marsella, que se produciría en 1080. La fecha resulta clave para los historiadores que consideran 1076 como el año de la adopción oficial ${ }^{17}$ de la liturgia romana en el reino castellano-leonés. Por entonces, en los meses de mayo o junio, Alfonso VI debió manifestar públicamente su decisión en la ciudad de Burgos ante una asamblea de nobles y eclesiásticos ${ }^{18}$. Semejante postura está respaldada por la oposición surgida en diferentes sectores sociales, que testimo-

núm. 1.513; olim F-134), hay una miniatura justo antes de este fragmento que representa a un rey sentado y a dos frailes en pie. La leyenda es: Adefonsus Rex. Para Sánchez Alonso se refiere, sin duda, a los monjes que Gregorio VII envió a Alfonso VI; SÁnchez Alonso, 80, nota I.

16 Este hecho ha sido puesto de relieve por el profesor Reilly, quien señala la coincidencia con $C S_{1}$; REILLY, 13.

17 Cuando nos referimos a la introducción del rito romano en Castilla a menudo la identificamos con la sanción ordenada por Alfonso VI y las vicisitudes que la acompañaron. Esto es lo que entiendo por introducción oficial, porque el rito importado no comenzó a celebrarse de forma inmediata. Hacía falta todo un proceso de aprendizaje y de asimilación; se necesitaban libros para los templos catedralicios, monásticos y parroquiales. El largo período de implantación y asimilación vital por parte de cada iglesia local, de cada diócesis lo podemos denominar introducción de facto o proceso de recepción.

18 A. Linage, Alfonso VI, el rey hispano y europeo de las tres religiones (1065-1109), Burgos, 1994, 98, 102. Este decreto ha sido interpretado como una decisión de principio, tal vez en el sentido de primera declaración oficial; P. DAVID, Études historiques sur la Galice et le Portugal du VIe au XIIe siècle, Lisboa-Paris, 1947, 399; L. SERRANO, El obispado de Burgos y Castilla primitiva desde el siglo V al XIII, Madrid, 1935, t. I, 298.

Hispania Sacra, Medievalia hispanica, 58

117, enero-junio 2006, 9-35, ISSN: 0018-215-X 
nia el mismo monarca en su carta al abad Hugo de Cluny, del 10 de julio de $1077^{19}$.

Sin embargo, el padre Flórez, en su edición de la $C P$ enmienda la fecha y lee MCXXIII en lugar de MCXVIII, es decir, 1085 en lugar de $1076^{20}$. A partir de esta versión errónea, Demetrio Mansilla corrige 1080 en lugar de 1085 y añade que «los hechos transmitidos por el Cronicón del obispo de Oviedo, don Pelayo, se limitan a consignar la abolición del rito mozárabe en un concilio celebrado en Burgos. La asamblea conciliar fue convocada y presidida por el legado cardenal Ricardo que, a pesar del rey Alfonso VI, fue enviado por el Papa Gregorio VII» ${ }^{21}$. En realidad, la postura de Mansilla es explicable dado su propósito de justificar un único y gran concilio burgalés. Se trata de un error común, ya que no pocos investigadores han orientado sus esfuerzos a determinar la fecha de dicha asamblea conciliar única. En este asunto, la aportación más original sigue siendo la de Reilly, quien estima que se suele contemplar la institución conciliar de esta época desde unos parámetros posteriores, sin que se hayan sabido apreciar «ni los sencillos usos del siglo XI, ni la holgura de su lenguaje». Para este autor, «en rigor puede que se tratara de un conjunto de decisiones adoptadas en la corte por los obispos allí presentes en cierta ocasión, y luego ratificadas en ocasión distinta, aunque ambos actos tuviesen lugar en Burgos» ${ }^{22}$. La aparente inexistencia de cánones o actas de aquella asamblea sería un dato a favor de esta hipótesis.

\subsection{Crónica de Sahagún (s. XII)}

Las dos crónicas anónimas de Sahagún ${ }^{23}$ narran la historia del célebre cenobio leonés desde finales del siglo XI hasta mediados del XIII. En el siglo XVII, el monje benedictino José Pérez, el primero que tuvo el propósito de publicar ambas obras, afirmó que el autor de la primera vivía en la época de Alfonso VI y de su hija doña Urraca (1109-1126), puesto que se halló presente a la muerte

\footnotetext{
19 «Por lo que se refiere al rito romano, que según tu mandato recibimos, habéis de saber que nuestra tierra se encuentra en la mayor desolación. Por lo cual suplico a vuestra paternidad que consigáis que el papa nos envíe su cardenal, es decir, a Giraldo, para que enmiende lo que hay que enmendar y corrija aquello que ha de ser corregido»; texto latino en A. GAMBRA, Alfonso VI: Cancillería, curia e imperio. Vol. II, Colección diplomática, León, 1998, n. ${ }^{\circ}$ 47, 123.

${ }^{20}$ FLÓREZ, ES XIV, 488.

21 D. Mansilla, «El reino de Castilla y el Papado en tiempos de Alfonso VI (1065-1109)», en Estudios sobre Alfonso VI y la reconquista de Toledo I. Actas del II Congreso Internacional de Estudios Mozárabes (Toledo, 20-26 mayo 1985), Toledo, 1987, 55-56.

22 ReILly, 121.

23 La crónica que data del siglo XII se encuentra en: J. PuYOL y ALONSO, «Las crónicas anónimas de Sahagún», BRAH 76 (1920) 7-26, 111-122, 242-257, 339-356, 395-419, 512-519; BRAH 77 (1921) 51-59, 151-161.
} 
del monarca, y que al parecer fue compañero del arzobispo don Bernardo de Toledo (1086-1125) ${ }^{24}$.

En relación con el texto, ambas crónicas nos han llegado en su traducción al romance antiguo a partir del original latino. El fragmento a propósito del cambio ritual es el que sigue:

$C S_{1}, \S 4^{25}$ :

El qual [Alfonso VI], despues que suuio en el alteça e magnifico estado rreal de su rreyno, entre otras cosas muchas que muy loable e rreligiosamente fiço, en el onçeno año de su rreino procuro, suplicando al baron de muy onrrada vida Gregorio setimo en la silla apostolical, que en toda España fuese çelebrado el diuinal ofiçio segun que la iglesia rromana acostumbraba, e aun con [quizá sea como] de cauo enflamado por çelo e deuoçion de la santa rreligion, en el quinçeno anno de su rreino enbio a Cluni, mucho rogando al uaron don Hugo, abbad del monasterio del dicho Cluni, que por su contenplaçion le pluguiese enbiarle algunos monjes, los quales mostrasen e enseñasen la rreligion, costunbres e çeremonias del dicho monasterio de Cluni en este monasterio [Sahagún], del cual abemos fecho largo fabla [...].

El relato está inserto en la primera de las doce secciones que narran la historia del monasterio leonés en tiempos de Alfonso VI. El monje cronista se muestra plenamente favorable al monarca, refiriéndose a él como muy noble rey, muy noble guerrero, discreto, recto de juicio, astuto y entendido en los negocios seglares, religioso y piadoso en las cosas eclesiásticas. Entre las cosas que el autor destaca en su gobierno está su solicitud al papa Gregorio VII de la adopción en sus reinos de la liturgia romana. Se trata de una decisión que se valora positivamente junto con la reforma cluniacense del monasterio de Sahagún, llevada a cabo por el mismo rey, inflamado por el celo y devoción de la santa religión.

De nuevo aquí debemos poner de relieve dos elementos claves: primeramente, que el autor anónimo de esta crónica atribuye la iniciativa al rey. Este dato adquiere mayor valor teniendo en cuenta que el cronista desconocía la $C P$. En segundo lugar, $S C_{1}$ coincide también con la obra pelagiana en relación con la fecha de 1076 (en el onçeno año de su rreino) ${ }^{26}$.

24 Puyol y Alonso, 10-11. También Reilly cree que este monje anónimo fue probablemente contemporáneo de Alfonso; ReILLY, 13.

25 Puyol y ALONSO, 114.

26 ReILly, 121. Pierre David comparte la tesis de 1076 como fecha de la manifestación pública de la resolución real de imponer el rito romano. Sin embargo, hace notar que el cronista de Sahagún señala 1066 como inicio del reinado alfonsino; DAVID, 399. En realidad, el problema es más aparente que real, puesto que el undécimo año de reinado es precisamente 1076 y no 1077, considerando que el referido 1066 es ya el primer año de gobierno alfonsino.

Hispania Sacra, Medievalia hispanica, 58

117, enero-junio 2006, 9-35, ISSN: 0018-215-X 


\subsection{La Crónica Najerense}

Dentro de nuestro recorrido por la historiografía medieval, debemos avanzar varias décadas hasta el final de siglo XII para detenernos en una crónica en la cual tuvieron especial eco las vicisitudes de la supresión de la liturgia autóctona peninsular. Se trata de la $C N^{27}$, obra compuesta probablemente en el scriptorium de Santa María la Real de Nájera ${ }^{28}$ por un monje afecto a este monasterio riojano y con algún vínculo con Compostela, dado su conocimiento de códices y leyendas gallegas ${ }^{29}$. Algunos historiadores han apuntado también su condición de cluniacense de origen francés ${ }^{30}$. En cuanto a la fecha de composición de la $C N$, recientemente se ha tendido a retrasar hasta la década de los ochenta del siglo XII ${ }^{31}$, por tanto, aproximadamente un siglo después del cambio de rito. Nuestra atención debe dirigirse al libro III, el último de la crónica y el más original, consagrado principalmente a la descripción de los avatares del reinado de Fernando I (1037-1065) y que culmina con la muerte de su hijo Alfonso VI ${ }^{32}$ (1109). Respecto a las fuentes de este libro nos interesa saber por el momento que gran parte de la $C N$ tiene procedencia pelagiana, aunque no siempre ésta se verifique de forma directa ${ }^{33}$. Transcribo el texto en cuestión:

CN, III, $18^{34}$ :

Prefatus itaque rex Aldefonsus postquam regnorum suscepit regimina, nuntios Romam misit ad papam Aldebrandum qui cognominatus est Gregorius septimus, ut
Así pues, el mencionado rey Alfonso, tras asumir el gobierno de los reinos, envía una embajada a Roma al papa Aldebrando, quien recibía el sobrenombre de Gre-

27 La primera edición completa y con una excelente introducción se halla en: Chronica Hispana saeculi XII. Pars II. Chronica Naierensis, cura et studio J. A. EstéVEZ SolA, CCCM 71A, Turnhout, 1995. Otra buena edición pero sin la parte isidoriana es: Crónica Najerense, estudio preliminar, edición crítica e índices por A. UBiEto ArtetA, Textos Medievales 15, Valencia, 1966.

28 Así piensa Antonio Ubieto, basándose en los documentos manejados por el autor, así como por algunos textos utilizados; UBIETO ARTETA, 26-27.

${ }^{29}$ ESTÉvez Sola, CCCM 71A, XCIV.

30 C. Orcástegui - E. Sarasa, La Historia en la Edad Media, Madrid, 1991, p. 202. Los argumentos de esta hipótesis son dados por UBIETo ARTETA, 29-30.

31 EstéveZ SOLA, CCCM 71A, LXX-LXXIX.

32 Hay que notar a este propósito que el castellanismo filonobiliario de la $C N$ es tan agudo que le impide verter el menor elogio sobre Alfonso VI, ni siquiera con motivo de la imposición del rito romano o la entrega a Cluny del monasterio de Nájera, hecho que afectaba al autor personalmente; M. A. RODRÍGUEZ DE LA PEÑA, «Ideología política y crónicas monásticas: la concepción cluniacense de la realeza en la España del siglo XII», Anuario de Estudios Medievales 30/2 (2000) 731. Detrás de esta actitud está el cambio producido en el siglo XII: la maiestas propia de la visión isidoriana de la Realeza se va a contraponer al programa gregoriano del «Rey tutelado» que van a imponer con entusiasmo los monjes cluniacenses; Ibid., 687.

33 Estévez Sola, CCCM 71A, LII.

34 EsTÉvez SOLA, CCCM 71A, 177; la traducción en: Crónica Najerense, edición de J. A. EsTÉVEZ Sola, CLMR 12, Madrid, 2003, 180. 
Romanum ministerium in omni regno suo constitueret celebrandum. Memoratus itaque papa cardinalem suum Ricardum, abbatem Massiliensem in Yspaniam misit; qui apud Burgensem ciuitatem nobile et generale concilium celebrans diuinum officium iuxta Romanam consuetudinem in omni regno predicti regis haberi mandauit.

Era MCXV.a in Dominica de ramis palmarum apud Burgis pugnauerunt duo milites, unus regis Aldefonsi pro lege Romana et alter Castellanus, scilicet Lupus Martinez de Matanza, pro lege Toletana; et uictus est miles regis. Super quo illis adhuc contendentibus, accenso magno igne in platee medio missi sunt in eum duo libri, unus Romanum officium continens alter uero officium continens Toletanum, sub tali conditione: ut cuius modi liber ignem illesus euaderet, eius officium teneretur. Sed cum Toletanus magnum extra ignem saltum dedisset, mox rex iratus illum in ignem pede reiciens dixit: «ad libitum regum fletantur cornua legum». gorio VII, para que implantara la celebración por rito romano en todo su reino. Entonces el papa se acordó de su cardenal Ricardo, abad marsellés, y lo envió a Hispania; éste celebró en la ciudad de Burgos un concilio de obispos y nobles y mandó que el oficio divino se celebrara según el rito romano en todo el reino del rey antes mencionado.

En la era 1115, el Domingo de Ramos [9 de abril de 1077], en Burgos lucharon dos caballeros, uno del rey Alfonso en defensa de la ley de Roma y el otro castellano, Lope Martínez de Matanza, en defensa de la ley de Toledo; y fue vencido el caballero del rey. Además, mientras ellos estaban aún luchando, se encendió un gran fuego en medio de la plaza y se echaron en él los dos misales, el uno que contenía el oficio romano y el otro que contenía el oficio toledano, con esta condición: que se implantara el oficio del misal que saliera indemne del fuego. Pero como quiera que el toledano dio un gran salto fuera del fuego, al punto el rey, airado, lo devolvió al fuego de una patada diciendo: «A la voluntad de los reyes se doblan los cuernos de las leyes».

Esta referencia a la problemática ritual, la más extensa que hasta ahora hemos encontrado, presenta dos partes de distinta naturaleza y procedencia. De hecho, el profesor Antonio Ubieto las ha distinguido en su edición de la $C N^{35}$. La primera de ellas finaliza con la alusión a la sanción real en un concilio celebrado en Burgos. La segunda, muy conocida y divulgada, narra dos ordalías acontecidas en la misma ciudad el 9 de abril de 1077. Quiero detenerme, en primer lugar, en diferenciar lo que hay de dependencia y novedad en este relato respecto a los anteriormente estudiados. Estévez Sola ha señalado que la $C P$ es la fuente más cercana de la $C N$, aspecto evidente sobre todo para la vida de Alfonso VI (III, 18-23) ${ }^{36}$. En efecto, en la primera sección podemos comprobar que toda la narración de don Pelayo ha sido incorporada por el Najerense, a veces incluso literalmente:

\footnotetext{
35 Corresponden a los párrafos 48 y 49 del libro III; UBIETo ARTETA, 116.

36 EsTÉvez Sola, CCCM 71A, LV.
}

Hispania Sacra, Medievalia hispanica, 58

117, enero-junio 2006, 9-35, ISSN: 0018-215-X 
$C P$, Adefonsus VI:

Tunc Adefonsus rex uelociter Romam nuncios misit ad Papam Aldebrandum cognomento Septimus Gregorius;

ideo hoc fecit, quia romanum misterium habere uoluit in omni regno suo.

Memoratus itaque Papa Cardinalem suum Ricardum, Abbatem Marsiliensem, in Hispana transmisit.

Qui apud Burgensem urbem Concilium celebrauit confirmauitque romanum misterium in omni regno regis Adefonsi Era MCXIIII.
CN, III, 18

Prefatus itaque rex Aldefonsus postquam regnorum suscepit regimina, nuntios Romam misit ad papam Aldebrandum qui cognominatus est Gregorius septimus,

ut Romanum ministerium in omni regno suo constitueret celebrandum.

Memoratus itaque papa cardinalem suum Ricardum, abbatem Massiliensem in Yspaniam misit;

qui apud Burgensem ciuitatem nobile et generale concilium celebrans diuinum officium iuxta Romanam consuetudinem in omni regno predicti regis haberi mandauit.

Ahora bien, el cronista de Nájera suele tomarse libertades en ampliar las fuentes que maneja o añadir otras noticias. Es precisamente lo que sucede en la segunda sección, en la cual aparecen las dos ordalías, también llamadas juicios de Dios: el duelo entre los dos caballeros a propósito del rito que debía seguirse y la posterior ordalía de la hoguera. Constatamos, por consiguiente, que la primera parte del relato proviene de la $C P$, mientras que de la segunda desconocemos su fuente precisa. Lo más probable es que se trate de la inclusión de una narración legendaria procedente de la épica hispana. En efecto, el autor de la $C N$ muestra un espíritu amplio en dar profusa acogida a este tipo de relatos ${ }^{37}$. El proceso en este caso se adecúa muy bien a una de las características analizadas por Estévez Sola acerca de los apuntes de carácter épico que aparecen en la $C N$ : «Entre el hecho histórico y la aparición del tema en la historiografía suele transcurrir por lo menos un siglo, período de gestación de la leyenda y de su acuñación como verdad histórica» ${ }^{38}$.

Respecto a la parte que depende directamente del Ovetense, únicamente deseo llamar la atención sobre la ausencia de la fecha en que tuvo lugar la trascendental asamblea de Burgos. No obstante, por el contexto deducimos que fue antes de abril de 1077, cuando ya se estaba produciendo la resistencia a la decisión real. Este dato concuerda con la mencionada carta de Alfonso VI a Hugo de Cluny (10-7-1077).

Ahora bien, ¿qué interpretación podemos hacer de la segunda sección? ¿Es sostenible la afirmación de un núcleo histórico en ella? En opinión de Reilly, el texto evidentemente incorpora material literario, pero no es improbable que se celebraran dichos actos ${ }^{39}$. De hecho, Alfonso VI estaba en Burgos en la prima-

37 Estévez Sola, CCCM 71A, LXXXV-LXXXVI; Estévez Sola, CLMR 12, 27-31.

38 EstÉvez SOLA, CLMR 12, 28.

39 ReILly, 122, nota 33. 
vera de ese año y la práctica de las ordalías estaba generalizada ${ }^{40}$. En cualquier caso, la narración resulta importante porque nos aproxima a una situación real. Así piensa Guy de Valous, al afirmar que este relato, amplificado o no, e incluso siendo legendario, tiene al menos el interés de describirnos el estado de sobreexcitación que los objetivos unificadores de Gregorio VII provocaron entre los españoles ${ }^{41}$. También el hecho de que tanto en el duelo como en la ordalía de la hoguera se vean frustrados los deseos del monarca parece reflejar «la verdad esencial de la situación existente en aquel momento» ${ }^{42}$, es decir, la existencia de un frente opuesto a la supresión de la liturgia propia tradicional ${ }^{43}$.

El final del relato tiene también su interpretación histórica. La reacción del monarca, que aparece airado (iratus) devolviendo al fuego de una patada el misal del oficio toledano mientras pronuncia el conocido refrán en su versión culta (ad libitum regum fletantur cornua legum), prueba que Alfonso VI no aceptaba el resultado de ninguna de las ordalías porque no estaba dispuesto a echarse atrás en su decisión sobre la cuestión ritual. Más bien, por el contrario, se le ve dispuesto a imponer su voluntad, pasando por encima de cualquier resistencia.

\subsection{Valoración del siglo XII}

Llegados al fin de esta centuria, constatamos en primer lugar, a partir de los textos analizados, la escasez de noticias conservadas en la historiografía castellano-leonesa sobre la adopción de la liturgia romana. Son realmente pocas las obras en las que encontramos ecos de tal acontecimiento. Dejando a un lado la $H C$ que no aporta ningún dato relevante, la verdadera recepción de los hechos se produce en la $C P$ y $C S_{1}$, las dos narraciones más tempranas que constituyen el punto de partida de nuestro itinerario a través de la historiografía medieval. Ciertamente se trata de una recepción que representa, por así decir, la versión oficial, caracterizada por la tendencia a destacar la figura del rey Alfonso VI y que comparten los dos autores, el obispo de Oviedo y el monje benedictino de Sahagún. Ahora bien, ambas obras proporcionan algunos datos fundamentales: un claro protagonista (Alfonso VI), una fecha (1076) y una ciudad en la que celebra una asamblea conciliar (Burgos). Notemos que la versión de estos relatos

40 Tales prácticas serían suprimidas en la primera mitad del siglo XIII, a raíz del concilio IV de Letrán (1215), que en su canon 18 prohibe a todo miembro del clero prestar su ministerio para bendecir o consagrar los elementos u objetos que sirven para la ordalía; H. LECLERCQ, «Ordalie», en Dictionnaire d'Archéologie Chrétienne et de Liturgie XIII, 2390.

${ }^{41}$ G. DE VAlous, «Les monastères et la pénétration française en Espagne du XI ${ }^{\mathrm{e}}$ au XIII ${ }^{\mathrm{e}}$ siècle», Revue Mabillon 30 (1940) 91.

42 ReILly, 122.

$43 \mathrm{Me}$ he ocupado de este interesante tema en mi estudio: J. P. RuBIO SADIA, Las órdenes religiosas y la introducción del rito romano en la Iglesia de Toledo, Toledo, 2004, 57-68.

Hispania Sacra, Medievalia hispanica, 58

117, enero-junio 2006, 9-35, ISSN: 0018-215-X 
contrasta con diversos textos del epistolario del papa Gregorio VII, quien desde 1074 no cejó en su empeño de lograr la romanización litúrgica de la Península, para lo cual se expresó con una dureza excesiva hasta el extremo de amenazar al rey castellano con venir personalmente a España y desenvainar contra él la espada de san Pedro ${ }^{44}$.

A su vez, la $C N$ introduce en nuestro itinerario un elemento legendario que va a tener gran éxito en el siglo siguiente y que se va a convertir en el relato más popular y difundido sobre este tema. Sin embargo, el carácter legendario no debe llevar al historiador a menospreciar esta narración. Detrás del material literario podemos percibir aspectos históricos de la situación real que se generó a raíz del mandato de Alfonso VI de importar una liturgia extranjera.

Por otra parte, debemos decir una palabra sobre un silencio llamativo. Me refiero a la Historia Silense, compuesta hacia 1115 probablemente en el monasterio de San Juan de León, cuyo objetivo primordial no es otro que proclamar las hazañas de Alfonso VI. En realidad, se trata de una obra singular dentro de la historiografía latina medieval. El motivo de fondo de la ausencia de un hecho tan relevante del reinado alfonsino como fue el cambio de liturgia radica en el propio autor, el cual se muestra defensor ardiente de lo leonés pero, al mismo tiempo, enemigo sutil de todo lo franco y, por tanto, también de la liturgia galicana $^{45}$.

En resumen, en el siglo XII podemos afirmar que el iter historiográfico del cambio de rito cuenta con dos momentos significativos: la $C P$ y la $C S_{1}$ constituyen el punto de partida y la recepción oficial de los hechos a los pocos años de haber sucedido. En cambio, la $C N$, a distancia casi de un siglo, aun siendo heredera de la $C P$, representa un cambio, al dar entrada a un material legendario que parece haberse liberado de la postura oficial necesariamente favorable al rey Alfonso. Este material nos aproxima de alguna manera a un sentir popular contrario a la mutación litúrgica, porque el pueblo fue susceptible de ser movilizado por los sectores eclesiásticos más disconformes con la sanción real, aunque este fenómeno no debemos generalizarlo ni exagerarlo.

\footnotetext{
${ }^{44}$ La postura y el pensamiento del papa Gregorio VII han sido bien sintetizados por J. M. Soto RÁBANOS, «Introducción del rito romano en los reinos de España. Argumentos del papa Gregorio VII», en Studi Gregoriani per la Storia della «Libertas Ecclesice», XIV (1991), 161-174.

45 M. DíAz Y DíAZ, «Crónicas», DHEE I, 644.
} 


\section{CRÓNICAS Y CRONICONES DEL SIGLO XIII}

\subsection{La Crónica de Sahagún (continuación del s. XIII)}

La segunda crónica del monasterio de Sahagún ha sido publicada también por Julio Puyol y Alonso ${ }^{46}$. El padre José Pérez, ya mencionado a propósito de la crónica del siglo XII, sostenía que el autor de esta segunda obra escribió hacia 1240 y fue compañero de dom Nicolás, abad de Sahagún ${ }^{47}$. La traducción al romance antiguo que nos ha llegado en esta segunda narración aventaja notablemente a la de la primera ${ }^{48}$. La referencia al cambio de rito está justamente al comienzo de la obra:

\section{$C S_{2}, \S 1^{49}$ :}

En la era de mill y çiento e seis, el rrei don Alfonso, fijo del rrey don Fernando, en este monesterio, consagrado a honor e rreberençia de los santos martires Facundo, conbiene a saber, e Primitiuo, alunbrado por graçia diuinal, fiço rresplandeçer la horden monacal, primeramente por mandato de don Fernando, abad, e despues procuro que se çelebrase el ofiçio rromano en España por autoridad de Ricardo, vicario de la iglesia rromana, e por quanto vio que aqui se auia la horden monacal pereçosamente, otra bez, mouido por graçia diuinal, procuro rreformar la dicha horden por algunos barones sauios e rreligiosos, a semejança de la rregla de Cluni, de la orden de Sant Benito.

De nuevo, el personaje que resalta en este texto es Alfonso VI, presentado como un instrumento de la providencia de Dios. Por dos veces se dice que actúa alumbrado o movido por la gracia divina. El monarca es sujeto de tres importantes intervenciones: actuación a favor de Sahagún en 1068 (fiço rresplandeçer la horden monacal); introducción del rito romano (despues procuro que se çelebrase el ofiçio rromano en España); reforma cluniacense del monasterio leonés (procuro rreformar la dicha horden [...] a semejança de la rregla de Cluni). La primera de estas actuaciones podría hacer referencia a la concesión de un importante privilegio de inmunidad a las villas del monasterio el 22 de noviembre de $1068^{50}$, «una cierta decisión restauradora» según Antonio Linage ${ }^{51}$. La segunda, la que nos interesa, se refiere al cambio de liturgia. La alusión es muy breve, puesto que el autor no pretende detenerse en este tema, tratado ya en la $C S_{1}$. La fecha queda indeterminada. No obs-

\footnotetext{
46 J. PuYOl y Alonso, «Las crónicas anónimas de Sahagún», BRAH 77 (1921), 162-192.

47 PuYol y Alonso, BRAH 76 (1920), 11.

48 PuYol y Alonso, BRAH 76 (1920), 17.

49 Puyol y Alonso, BRAH 77 (1921), 162.

50 GAMBRA, n. ${ }^{\circ} 6,14$.

51 A. Linage, Los orígenes del monacato benedictino en la Península Ibérica. Vol. II, La difusión de la «Regula Benedicti», León, 1973, 951.
} 
tante, hay que reconocer que la frase presenta cierta ambigüedad, que radica en la expresión: por autoridad de Ricardo. Bernard F. Reilly la interpreta en el sentido de que es el cardenal quien proclama el nuevo rito, probablemente en 1080 durante su segunda visita al reino castellano-leonés ${ }^{52}$. En ese mismo año tuvo lugar la reforma cluniacense de Sahagún, que se menciona justo a continuación. De ser ésta la interpretación correcta, es posible pensar en un cambio significativo respecto a la versión oficial que atribuía el protagonismo del cambio de rito al rey. Pero la expresión puede tener otro sentido, dado que el sujeto de la frase es el monarca castellano; es él quien procura que se celebre el oficio romano en España ${ }^{53}$. En este sentido, cabe la posibilidad de considerar que el cardenal Ricardo lo que hace en virtud de su autoridad de legado es dar la aprobación pontificia a la sustitución ritual decidida y ejecutada por el poder temporal.

\subsection{Los cronicones}

El género de los cronicones tuvo una gran difusión en los diferentes reinos peninsulares durante el período histórico que nos ocupa. El profesor Manuel Díaz y Díaz los ha caracterizado como un «género seco y esquelético», «consistente en breves noticias yuxtapuestas sin matización, clasificadas por los años en que tuvieron lugar ${ }^{54}$. Ciertamente las noticias que nos proporcionan acerca del cambio de liturgia responden a la peculiaridad de este género historiográfico. En este epígrafe vamos a fijarnos en tres de ellas, las que se encuentran en $C B, A C$ y $C C$.

$C B$, [años $1077-1078]^{55}$ :

Era MCXV. Fuit hiems gravissima a festivitate S. Martini usque ad Quadragesimam, \& in ipso anno pugnaverunt duo milites pro lege Romana, \& Toletana in die Ramis Palmarum, \& unus eorum erat Castellanus, \& alius Toletanus, \& victus est Toletanus a Castellano.

Era MCXVI. Intravit Romana lex in Hispania.
Año 1077. El invierno fue muy duro desde la fiesta de san Martín hasta Cuaresma, y en ese mismo año lucharon dos soldados a favor de la ley romana y de la toledana el domingo de Ramos; uno de ellos era castellano y otro toledano y el toledano fue vencido por el castellano.

Año 1078. Entró la ley romana en España.

52 ReILly, 125, nota 45.

$53 \mathrm{Al}$ igual que sucede en el castellano de la $C S_{1}$ o en el latín del $C B$, España o Hispania se refieren a los estados gobernados por el monarca Alfonso VI, es decir, León, Castilla y Galicia.

54 DíAz Y Díaz, 645.

55 H. FlóREZ (ed.), Chronicon Burgense, ES XXIII, Madrid, 1799, 310. 
$A C$, [año 1077] ${ }^{56}$ :

Era MCXV. Fuit hyems gravissima a festivitate S. Martini usque ad Quadragesimam, \& in ipso anno pugnaverunt duo milites pro lege Romana, \& Toletana in die Ramis Palmarum: unus eorum erat Castellanus, alter Regis Aldefonsi.

$C C$, [año 1078$]^{57}$.

Era de MCXVI. entró la ley Romana en España.

\begin{abstract}
Año 1077. El invierno fue muy duro desde la fiesta de san Martín hasta Cuaresma, y en ese mismo año lucharon dos soldados a favor de la ley romana y de la toledana el domingo de Ramos; uno de ellos era castellano y el otro del rey Alfonso.
\end{abstract}

En Castilla, después de la batalla de Las Navas (1212), es cuando se escribe el $C B$. Este cronicón incorpora dos noticias para los años 1077 y 1078: el famoso duelo entre caballeros y la introducción del rito romano en Hispania. Por su parte, los mal llamados $A C$, compuestos hacia $1248^{58}$, recogen únicamente el relato del duelo con un texto prácticamente idéntico al del $C B$. Es probable que ambas obras hayan tomado su información de la $C N$ o directamente de otras fuentes literarias comunes a ésta última ${ }^{59}$.

Con respecto al texto vemos que en ningún caso se hace referencia ni a Alfonso VI ni al cardenal Ricardo, ni a la ciudad de Burgos. Todo se reduce al duelo celebrado el domingo de Ramos de 1077 con una escueta referencia a los caballeros. En caso del $C B$ resulta un tanto extraño que el caballero defensor del rito romano sea precisamente un toledano (que acaba siendo vencido), mientras que el defensor de la liturgia toletana es un caballero castellano. No encuentro otra explicación que la ya dada por Pierre David: puede tratarse simplemente de un cristiano de Toledo incorporado al servicio del rey ${ }^{60}$.

Las variantes textuales de los $A C$ se encuentran al final. En lugar del caballero toledano del $C B$, se menciona a un caballero que lucha por parte del rey (alter Regis Aldefonsi). Los $A C$ cortan aquí su noticia sin atribuir la victoria a ninguno de los dos combatientes ${ }^{61}$. Además no existe una alusión explícita a la introducción del rito romano. Es probable que esta concisión se deba tanto al género historiográfico como a la popularidad de una historia que no precisaba de muchos detalles. Sobre el llamado $C C$, del cual quizá circuló un primer nú-

56 H. FLóREZ (ed.), Annales Compostellani, ES XXIII, Madrid, 1799, 321-322.

57 H. Flórez (ed.), Chronicon de Cardeña, ES XXIII, Madrid, 1799, 373.

58 DíAZ y DíAZ, 645. La datación de este cronicón ha sido problemática. Tanto Pierre David como Antonio Ubieto lo remontan al siglo XII, considerándolo anterior a la $C N$ y una de sus fuentes; DAVID, 400; Ubieto Arteta, 12, 20, 28.

59 REILLY, 122, nota 33.

60 DAVID, 400.

61 DAVID, 400.

Hispania Sacra, Medievalia hispanica, 58

117, enero-junio 2006, 9-35, ISSN: 0018-215-X 
cleo escrito en latín, es probable que su noticia haya sido tomada directamente del $C B$.

Consideremos ahora más detenidamente la cuestión cronológica que se plantea a partir de estas noticias. Como ya hemos indicado, los $A C$ no aluden explícitamente a la introducción del rito romano. Sin embargo, Reilly afirma que el autor de esta obra data el cambio ritual en $1077^{62}$, lo cual no deja de ser una conjetura sin base en el propio texto. En ese año sólo se menciona el duelo entre caballeros. En cambio, el $C B$ y el $C C$ sí consignan la entrada de la lex romana en 1078 , fecha importante por coincidir con la primera legación del cardenal Ricardo. De hecho, don Ramón Menéndez Pidal, basado en estas fuentes, sostenía que fue entonces cuando se llevó a cabo la sustitución: «La resistencia nacional se manifestaba principalmente en Castilla, en Burgos, como vemos. Por esto, acaso, era menos grata al rey. Empeñado Alfonso en vencerla, pidió al papa que le enviase como legado al cardenal Ricardo [...], el cual vino en mayo de 1078. Y el nuevo rito, al fin, a pesar de la muerte de la reina Inés (7 de junio), se propagó entonces por León y por Castilla. Los cronicones castellanos registran secamente el hecho, en el año 1078: entró la ley romana en España; pero tan breve frase encierra la expresión de una de las más hondas crisis de nacionalismo» ${ }^{63}$. Por su parte, Demetrio Mansilla, refiriéndose a esta escueta noticia de 1078, afirma que «los cronistas de la época con un laconismo muy seco, pero muy expresivo, consignan el hecho de la introducción del rito romano» en Castilla ${ }^{64}$. Para valorar correctamente estas posturas, hay que tener en cuenta primero que estamos ante fuentes posteriores a los hechos históricos en más de un siglo. Asimismo, debemos considerar el estilo propio de los cronicones, que no parece justificar una visión histórica nacionalista tendente a dramatizar la supresión del rito hispano. Por último, respecto al $C B$ hemos de admitir que no contradice a la noticia de las primeras crónicas del siglo XII que consignan el año 1076 como la fecha de la comunicación oficial de adoptar la liturgia romana. El hecho de que el duelo suceda en 1077 confirma que hubo un comunicado previo por parte del rey, a raíz del cual surgieron reacciones opuestas que llevaron a actos como el duelo referido.

\subsection{El Chronicon Mundi, de don Lucas de Tuy}

Antes de abordar la extensa narración de don Rodrigo Jiménez de Rada sobre el cambio de rito, vamos a detenernos brevemente en un pasaje interesante

\footnotetext{
62 ReILly, 121, nota 31.

63 R. MENÉndez PidAl, La España del Cid, I, Madrid, 1947, 239.

64 D. MAnsilla, «El reino de Castilla y el Papado en tiempos de Alfonso VI (1065-1109)», en Estudios sobre Alfonso VI y la reconquista de Toledo I. Actas del II Congreso Internacional de Estudios Mozárabes (Toledo, 20-26 mayo 1985), Toledo, 1987, 51.
} 
y controvertido del $C M$ de don Lucas, obispo de Tuy (1239-1249) ${ }^{65}$. Recordemos que la obra del Tudense constituye junto con la del arzobispo de Toledo uno de los últimos ejemplos de historia escrita en latín en la Edad Media hispana y cierra, por así decir, nuestro itinerario historiográfico. Don Lucas compuso su $C M$ a instancias de la reina doña Berenguela, hija de Alfonso VIII de Castilla, probablemente entre 1230 y 1239, siendo todavía canónigo de San Isidoro de León, y antes de ser nombrado obispo de la modesta sede gallega ${ }^{66}$. De los cuatro libros de que consta el $C M$, el más interesante es el último, dedicado a narrar la historia de los reinos hispanos desde don Pelayo y la batalla de Covadonga hasta la toma de Córdoba en 1236 por Fernando III. Dentro del libro IV, los capítulos 70-72 refieren la toma de Toledo y otras batallas, así como algunos episodios del Cid y la muerte del rey Alfonso VI. En esta sección el Tudense depende de la Historia Silense y de la $C P^{67}$. El texto que nos interesa sigue a la noticia de la muerte del rey García, hermano de Alfonso VI, acaecida en 1090, y del concilio celebrado en León en ese mismo año, presidido por el cardenal Rainerio, futuro papa Pascual II (1099-1118).

\begin{abstract}
CM, IV, 70, 39-4468:
In predicta uero synodo almi sacerdotes de fide catholica colloquentes statuerunt, ut secundum regulam beati Ysidori Yspalensis archiepiscopi ecclesiastica officia in Yspania regerentur.

Statuerunt etiam ut scriptores de cetero Gallicam litteram scriberent et pretermitterent Toletanam in officiis ecclesiasticis, ut nulla esset diuisio inter ministros ecclesie Dei.
\end{abstract}

Mas en el referido sínodo los santos sacerdotes, tratando de la fe católica, establecieron que en España los oficios eclesiásticos se ordenasen según la regla del arzobispo san Isidoro Hispalense.

Establecieron también que los copistas utilizaran la letra galicana en las demás cosas y abandonasen la toledana en los oficios eclesiásticos, a fin de que no hubiera ninguna división entre los ministros de la Iglesia de Dios.

Es muy llamativo, en primer lugar, comprobar que la asamblea conciliar de León, cuyas actas desconocemos, determina la práctica del oficio divino en España según la Regla de san Isidoro de Sevilla (secundum regulam beati Ysidori Yspalensis archiepiscopi), lo cual está en contradicción con todos los textos que hemos estudiado hasta ahora, puesto que implica aparentemente la permanencia de la práctica del rito tradicional hispano. El profesor Reilly considera que

65 Gracias al esfuerzo de la profesora Emma Falque, disponemos de una reciente edición crítica de esta obra acompañada de una amplia introducción: L. TuDENSIS, Chronicon mundi, cura et studio E. FALQUE, CCCM 74, Turnhout, 2003.

66 FALQUE, CCCM 74, XIX.

67 FALQUE, CCCM 74, LXXIII-LXXIV.

68 FALQUE, CCCM 74, 305.

Hispania Sacra, Medievalia hispanica, 58

117, enero-junio 2006, 9-35, ISSN: 0018-215-X 
el significado de esta disposición conciliar se nos escapa por completo ${ }^{69}$. No obstante, cabe interpretar el texto en el sentido de que aún existía una situación ambigua respecto del uso de las dos tradiciones litúrgicas, aunque «las palabras de los Padres conciliares pueden referirse al número y a la distribución de las horas del oficio» ${ }^{70}$. Es éste un punto sobre el que no parece posible dar una respuesta definitiva.

Por otro lado, la cuestión más relevante decidida por el concilio viene expresada a continuación. Consistió en desterrar el uso de la letra visigótica, llamada aquí Toletanam litteram, y sustituirla por la escritura carolina (Gallicam litteram $)^{71}$, hecho que atestigua también Jiménez de Rada. Emma Falque sostiene que este pasaje «se refiere a la sustitución de la liturgia mozárabe por la romana, de la que tanto se ha escrito y que don Lucas menciona de pasada [...] junto con la introducción de la letra carolina, que marcó un cambio importante en los usos gráficos» ${ }^{72}$. Semejante afirmación es evidentemente errónea, puesto que el texto en modo alguno menciona la sustitución de la liturgia hispana. En realidad, se trata de una confusión que no es nueva y que ya advirtió Antonio García y García ${ }^{73}$. Lo que hace don Lucas de Tuy es circunscribir la norma acerca de la grafía carolingia a los nuevos libros litúrgicos, mientras que el Toledano lo hace a todo tipo de libros. Por otra parte, el proceso de adopción de la grafía carolingia había comenzado bastante antes, dentro del marco de influjo francés en la Península, y aún había de prolongarse más de cuarenta años hasta llegar a reemplazar a la escritura visigótica. Por ello, para Reilly es dudoso que en el concilio se le prestara atención a este punto ${ }^{74}$, aunque no podemos descartar que en él se confirmara, estimulara y reforzara un cambio que ya se estaba operando ${ }^{75}$.

Finalmente, debemos señalar que el mismo Pierre David, buen conocedor de nuestras crónicas latinas medievales, afirma que el detalle del nombre de uno de los luchadores en el duelo de Burgos (Lupus Martinez de Matanza), recogi-

69 REILLY, 242.

70 A. OLIVAR, «La documentación litúrgica anterior al siglo XII relativa a la parte occidental de la península ibérica», en IX Centenário da dedicaçâo da Sé de Braga. Congresso Internacional. Actas. Vol. III: Teologia do Templo e Liturgia Bracarense, Braga, 1990, 76.

71 Como afirma el benedictino Alejandro Olivar, la decisión del concilio de León de que los nuevos libros litúrgicos se copiaran en caracteres carolingios era «una disposición de importancia con respecto al desarrollo histórico de la liturgia; una disposición que afectaba, de hecho, menos a los códices litúrgicos de tradición hispánica que a los de tradición romana, algunos de los cuales venían siendo ya escritos en letra visigótica (por amanuenses, sin duda, habituados a emplear solamente esta escritura)»; OLIVAR, 76-77.

72 FALQUE, CCCM 74, LXXV-LXXVI.

73 A. García y García, «Reforma gregoriana e idea de la Militia Sancti Petri en los reinos ibéricos», en Studi Gregoriani per la Storia della «Libertas Ecclesa», XIII (1989) 259.

74 ReILly, 242.

75 GARCÍA Y GARCíA, 260. 
do por vez primera en la $C N$, pasó a Lucas de Tuy y a Jiménez de Rada ${ }^{76}$. No hemos hallado en el Tudense ninguna referencia a dicho duelo ni a los caballeros. Todo lo cual nos lleva a concluir, por tanto, que el cambio de rito no tuvo resonancias en el $C M$, pese a que su autor tuviera delante la obra del obispo don Pelayo de Oviedo. Probablemente en este tema pesó más la influencia de la Historia Silense.

\subsection{De rebus Hispanie}

Con la obra $R H$ de don Rodrigo Jiménez de Rada ${ }^{77}$ (1170-1247), figura que domina toda la primera mitad del siglo XIII español, llegamos al término de nuestro estudio. A diferencia del $C M$ de don Lucas de Tuy, contemporáneo y amigo del arzobispo toledano, $R H$ contiene la narración más extensa de todas las que hemos analizado acerca del cambio de rito. Concretamente, se encuentra en el libro VI: en el capítulo 24 (Quod mezqvita Mavrorvm facta est ecclesia Christianorvm) y sobre todo en el capítulo 25 (De comvtatione officii Toletani).

$R H, \mathrm{VI}, \mathrm{XXIIII,} 1-8^{78}$ :

Et quia adhuc littera Gothica et translatio Psalterii et officium misse institutum ab Isidoro et Leandro, quod cum translatione et littera dicitur Toletanum, per totam Hispaniam seruabantur, ad instanciam uxoris sue regine Constancie, que erat de partibus Galliarum, misit Romam ad Gregorium Papam VII ut in Hispaniis onmisso Toletano Romanum seu Gallicanum officium seruaretur [...]

Y porque la letra gótica, la traducción del salterio y el oficio de la Misa instituido por Isidoro y Leandro, que en la traducción y en la letra se llama toledano, se guardaban todavía en toda España, a instancia de su mujer la reina Constanza, proveniente de las Galias, envió [legados?] a Roma, al papa Gregorio VII, para que en la Españas, omitido el rito toledano, se observase el romano o galicano [...]

$R H, \mathrm{VI}, \mathrm{XXV}, 1-60^{79}$ :

Gregorius autem septimus, de quo diximus, ad peticionem regis Aldefonsi misit quendam Ricardum, abbatem sancti Victoris Marsilensis, ut ecclesias Hispanie tot

Gregorio VII, a quien aludimos, según la petición del rey Alfonso envió a cierto Ricardo, abad de San Víctor de Marsella, para que pusiera en orden con la discipli-

76 DAVID, 401

77 Para los texto sigo la edición crítica del profesor Juan Fernández: R. XIMENEZ DE RADA, Historia de rebus Hispanie sive Historia Gothica, cura et studio J. Fernández VAlverde, CCCM 72, Turnhout, 1987.

78 Fernández VAlVerde, 205-206. Hay prácticamente una traducción en: Primera Crónica General de España, publicada por R. MENÉndez PIDAL, Madrid, 1955, t. II, 540.

79 Fernández VAlverde, 207-209. Véase también: Primera Crónica General de España, II, 542543.

Hispania Sacra, Medievalia hispanica, 58

117, enero-junio 2006, 9-35, ISSN: 0018-215-X 
persecucionibus perturbatas eclesiastico moderamine ordinaret. Qui minus religiose officium peragens cepit irregularius se habere. Quod atendens Toletanus electus per maris et terre pericula se Romani Pontificis conspectui presentauit; et Gregorio VII. ${ }^{\circ}$ uiam uniuerse carnis ingresso inuenit Vrbanum secundum in sede apostolica substitutum; a quo gratanter et benigne susceptus, consecrationem, pallium et priuilegium optinuit, et primas institutus Hispaniarum et apostolice sedis benedictione suscepta, per Tolosam rediens ibidem cum episcopis Gothice Gallie et Narbonensi archiepiscopo concilium celebrauit; inde per Pireneum in Hispanias transiens, omnium ecclesiarum Hispanie curam gessit, $[\ldots]$

Verum quia Ricardus legatus se gerebat in aliquibus minus caute, religione et auctoritate compescuit atemptata, adeo quod ille Ricardus legatione priuatus fuit ab Vrbano sunmo Pontifice reuocatus. Verum ante reuocationem clerus et populus tocius Hispanie turbabatur, eo quod Gallicanum officium suscipere a legato et principe cogebantur; et statuto die rege, primate, legato, cleri et populi maxima multitudine congregatis, fuit diucius altercatum, clero, milicia et populo firmiter resistentibus ne officium mutaretur, rege a regina suaso contrarium minis et terroribus intonante. Ad hoc ultimo res peruenit militari pertinacia decernente, ut hec dissensio duelli certamine sedaretur.

Cumque duo milites fuissent electi, unus a rege, qui pro officio Gallicano, alter a milicia el populis, qui pro Toletano pariter decertarent, miles regis ilico uictus fuit, populis exultantibus quod uictor erat miles officii Toletani. Set rex adeo fuit a regina na eclesiástica las iglesias de España perturbadas por tantas persecuciones. El cual, llevando a cabo su cometido de un modo menos religioso, comenzó a comportarse muy irregularmente. Al ver esto, el arzobispo electo de Toledo, a través de los peligros del mar y de la tierra, se presentó ante el romano Pontífice; mas habiendo entrado Gregorio VII en el camino de toda carne, encontró a Urbano II como sucesor en la Sede Apostólica. Recibido por el mismo grata y benignamente, obtuvo la consagración, el palio y el privilegio y fue instituido primado de las Españas, y después de haber recibido la bendición de la Sede Apostólica, regresando a través de Toulouse, celebró allí mismo un concilio con los obispos de la Galia gótica y el arzobispo de Narbona. Desde allí, pasando a través de los Pirineos a las Españas, asumió el cuidado de todas las iglesias de España [...]

Pero porque el legado Ricardo se comportaba de forma imprudente en algunos asuntos, habiendo sido atentada la religión y la autoridad, le frenó hasta tal punto que aquel Ricardo fue privado de sus funciones de legado y cesado por el Sumo Pontífice Urbano. Pero antes de esta revocación, el clero y el pueblo de toda España estaban alterados por el hecho de que se les obligaba por parte del legado y del príncipe a recibir el oficio galicano. $Y$ en un día determinado, congregados el rey, el primado, el legado y una gran multitud del pueblo, se produjo un altercado durante largo rato al resistirse firmemente el clero, la milicia y el pueblo para que no se cambiara el oficio, mientras el rey gritaba lo contrario con amenazas e intimidaciones, aconsejado por la reina. Por fin, el asunto llegó hasta tal punto, a causa de la pertinacia militar, que esta disensión se solventase con el certamen de un duelo.

Habiendo sido elegidos dos soldados, uno por el rey, que luchaba a favor del oficio galicano, y el otro por la milicia y el pueblo, que combatía igualmente por el oficio toledano, el soldado del rey fue vencido inmediatamente, exultando el pueblo porque

Hispania Sacra, Medievalia hispanica, 58 117, enero-junio 2006, 9-35, ISSN: 0018-215-X 
Constancia stimulatus quod a proposito non discessit, duellum iudicans ius non esse. Miles autem qui pugnauerat pro officio Toletano fuit de domo Matancie prope Pisoricam, cuius hodie genus extat.

Cumque super hoc magna sedicio in milicia et populo oriretur, demum placuit ut liber officii Toletani et liber officii Gallicani in magna ignis congerie ponerentur; et indicto omnibus ieiunio a primate, legato et clero et oratione ab omnibus deuote peracta, igne consumitur liber officii Gallicani et prosiliit super omnes flammas incendii, cunctis uidentibus et Deum laudantibus, liber officii Toletani illesus omnino et a combustione incendii alienus. Set cum rex esset magnanimus et sue uoluntatis pertinax executor, nec miraculo territus nec supplicatione suasus uoluit inclinari, set mortis supplicia et direptionem minitans resistentibus precepit ut Gallicanum officium in omnibus regni sui finibus seruaretur. Et tunc cunctis flentibus et dolentibus prouerbium inoleuit: «Quo uolunt reges uadunt leges».

Et ex tunc Gallicanum officium tam in Psalterio quam in aliis, numquam ante susceptum, fuit in Hispaniis obseruatum, licet in aliquibus monasteriis fuerit aliquanto tempore custoditum, et etiam translatio Psalterii in plurimis ecclesiis cathedralibus et monasteriis adhuc hodie recitatur. Ricardo itaque legatione priuato primas Bernardus cepit in Hispaniis ecclesias ordinare. el vencedor era el soldado del oficio toledano. Pero el rey fue animado de tal modo por la reina Constanza que no se apartó de su propósito, juzgando que el duelo no era justo. El soldado que había luchado a favor del oficio toledano fue de la casa de Matanza, cercana al Pisuerga, cuya familia aún perdura.

Habiéndose originado sobre esto una gran sedición en la milicia y en el pueblo, por fin plugo que el libro del oficio toledano y el del oficio galicano se pusieran en una gran hoguera. Y después de haber sido ordenado a todos un ayuno por el primado, el legado y el clero, y de haber hecho todos devotamente una plegaria, fue consumido por el fuego el libro del oficio galicano y saltó sobre todas las llamas del incendio, a la vista de todos que alababan a Dios, quedando en cambio, totalmente ileso y ajeno a la combustión del incendio el libro del oficio toledano. Pero como el rey era magnánimo y pertinaz ejecutor de su voluntad, no quiso doblegarse ni aterrorizado por el milagro ni persuadido por las súplicas, sino que amenazando con suplicios de muerte y expolios a los que se resistiesen, mandó que se observase el oficio galicano en todos los territorios de su reino. $Y$ entonces, ante el llanto y el dolor de todos, se acuñó el proverbio: "Las leyes van a donde quieren los reyes».

$Y$ desde entonces el oficio galicano, nunca anteriormente recibido, tanto en el salterio como en las demás partes, fue observado en las Españas, aunque en algunos monasterios haya sido observado [el hispano] durante algún tiempo, y también la traducción [hispana] del salterio se recita todavía hoy en muchas iglesias catedrales y monasterios. Habiendo sido, pues, privado Ricardo de su legación, el primado Bernardo comenzó a poner orden en las iglesias de las Españas.

Jiménez de Rada presenta, como vemos, dos alusiones diferentes y complementarias a la cuestión ritual en dos capítulos consecutivos. La primera es muy breve y encabeza la historia de la transformación de la mezquita de Toledo en

Hispania Sacra, Medievalia hispanica, 58

117, enero-junio 2006, 9-35, ISSN: 0018-215-X 
templo cristiano. Dicha historia está ampliada con la introducción de interesantes datos sobre la vida de Bernardo de la Sauvetat, monje cluniacense y primer arzobispo toledano tras la restauración de la sede (1086-1125). La segunda alusión constituye prácticamente todo un capítulo consagrado a las vicisitudes del cambio de liturgia, aunque en él se entremezclan otros relatos como la legación del cardenal Ricardo en la Península y la privación de sus funciones, el viaje de don Bernardo a Roma donde el papa Urbano II (1088-1099), antiguo compañero en Cluny, le instituye primado de las Españas (primas Hispaniarum), y finalmente, la consagración de la catedral de Toledo.

En relación con la técnica historiográfica debemos señalar que una de las características más importantes del Toledano es que siempre tiene delante dos o más fuentes ${ }^{80}$, lo cual comprobamos a propósito de nuestro tema. En efecto, en el breve fragmento del capítulo 24 se aprecia el influjo de la $C P$. En cambio, en el capítulo siguiente es muy probable que el arzobispo se haya servido de la $C N$, incorporando detalles tan precisos como el del soldado que luchó a favor de la liturgia toledana, perteneciente a la casa de Matanza ${ }^{81}$.

Así pues, de acuerdo con don Pelayo de Oviedo, $R H$ refiere que el rey Alfonso VI, a ruego de su esposa la reina Constanza (este aspecto lo trataré a continuación), solicitó al papa Gregorio VII que en sus territorios se observase el rito romano o galicano, aunque sin proporcionarnos ninguna fecha. Esta referencia se corresponde con la decisión real y la primera comunicación oficial que aconteció en 1076 de acuerdo con la $C P$ y la $C S_{1}$. Sin embargo, don Rodrigo mezcla sucesos, cambia acontecimientos de lugar y de fecha y exagera ciertos aspectos en función de su objetivo, como vamos a ver en seguida. Desde luego, lo más sorprendente de esta crónica es el hecho de que en el capítulo 25 los sucesos que siguieron a la decisión de Alfonso VI aparecen en unas nuevas coordenadas espacio-temporales. El ambiente de malestar y tensión generalizados ante la supresión del rito hispano, así como la escena del duelo y la ordalía del fuego ${ }^{82}$ ya no tienen lugar en la ciudad de Burgos en 1077 como sucedía en la $C N$, sino que tienen como escenario la ciudad de Toledo ${ }^{83}$. Todo parece confirmar que a don Rodrigo no le interesan los hechos en sí mismos, ni los datos

\footnotetext{
80 Tanto el $C M$ como la $C P$ forman dos ejes de su narración, aunque el primero constituye el telón de fondo en el que se van enmarcando las demás crónicas; FERNÁNDEZ VALVERDE, XXXIII.

81 Gómez Pérez se mostraba contrario a la opinión de que la $C N$ fuera conocida tanto por el Tudense como por don Rodrigo; J. Gómez PéREZ, «Manuscritos del Toledano», III, Revista de Archivos, Bibliotecas y Museos LXVII, I (1959) 202. No obstante, es casi seguro que Jiménez de Rada sí conocía la $C N$ aunque no le inspirara demasiada confianza y más bien le sugiriese ideas para desarrollar narraciones conocidas por él mediante fuentes legendarias o juglarescas; FERNÁNDEZ VALVERDE, XXXV-XXXVI.

${ }^{82}$ La narración de la ordalía del fuego especifica en este caso que estuvo precedida por un ayuno y por plegarias, algo usual en este tipo de prácticas.

83 Este hecho lo constató escuetamente Pierre David: «Rodrigue de Tolède, suivi par Mariana t. IX, place le duel et l'épreuve du feu à Tolède en 1086»; DAVID, 401, nota 2.
} 
cronológicos (que no especifica). Lo que realmente le importa es vincular a la sede primada que él gobierna, un acontecimiento tan relevante como fue el cambio de liturgia. Su finalidad, pues, no es otra que la defensa de la primacía eclesiástica de Toledo en un momento de insumisión por parte de los arzobispos de Tarragona, Braga y Compostela ${ }^{84}$. En la misma línea de enaltecer la sede primada debemos interpretar también la presencia y el protagonismo de don Bernardo en unos acontecimientos que le precedieron en más de un lustro. La figura del arzobispo toledano queda ensalzada sobre todo al final del capítulo 25, donde leemos que comenzó a poner orden en las iglesias de las Españas.

Al lado de esta intencionada transformación, don Rodrigo inserta otro aspecto novedoso que va a ir apareciendo a lo largo de toda su narración. Me refiero al influjo de la reina Constanza de Borgoña ${ }^{85}$. Es éste un dato interesante y, al mismo tiempo, difícil de enjuiciar. Las alusiones concretas a la acción de la reina son tres: ad instanciam uxoris sue regine Constancie, que erat de partibus Galliarum (VI, XXIII); rege a regina suaso (VI, XXV); set rex adeo fuit a regina Constancia stimulatus (VI, XXV). Constanza, protagonista junto a don Bernardo de la cristianización de la mezquita a espaldas del rey Alfonso en el capítulo 24, aparece en todo momento junto al monarca persuadiéndole a favor de la introducción de la liturgia galicana y alentándole ante la oposición tenaz del clero, el ejército y el pueblo. Juan Francisco Rivera Recio corrige que el texto del capítulo 24 se debe aplicar a Inés y no a Constanza ${ }^{86}$. Sin embargo, creo que este autor no tiene en cuenta la complejidad del relato ni los verdaderos objetivos del Toledano, que enlaza dos historias tan dispares como la de la decisión del monarca de adoptar la liturgia romana y la leyenda acerca de la cristianización de la mezquita mayor de Toledo. Desde el punto de vista cronológico, la reina Inés no podía estar presente en Toledo después de 1085, ya que había muerto en 1078. A favor de la historicidad de la influencia de Constanza en el cambio litúrgico puede aducirse el siguiente argumento: su origen francés, que le induciría a desear la liturgia que le era familiar. De hecho, sabemos que la reina se sentía «desterrada en un rincón de la tierra donde apenas ha llegado la doctrina apostólica». Éste fue probablemente uno de los motivos por los que solicitó la presencia en la Corte del monje benedictino francés san Les-

${ }^{84}$ Una síntesis de esta polémica puede verse en: J. F. RIVERA RECIO, «Primado de Toledo o Primado de las Españas», DHEE III, 2024-2027. El tema ha sido tratado con mayor amplitud por: D. MANSILLA, «Disputas diocesanas entre Toledo, Braga y Compostela en los siglos XII al XV», Anthologica Aпnиа, 3 (1955), 89-143; J. M. Soto RÁBANos, «Braga y Toledo en la polémica primacial», Hispania L/1 (1990) 5-37.

${ }^{85}$ Se trata de la segunda esposa del monarca, hermana del duque Eudes de Borgoña, con quien contrajo matrimonio a finales de 1079, tras la muerte de Inés de Aquitania el año anterior.

86 J. F. Rivera RECIO, «La supresión del rito mozárabe y la introducción del romano», en R. GARCía-Villoslada (dir.), Historia de la Iglesia en España. Vol. II-1. ${ }^{o}$, La Iglesia en la España de los siglos VIII al XIV, Madrid, 1982, 279-280.

Hispania Sacra, Medievalia hispanica, 58

117, enero-junio 2006, 9-35, ISSN: 0018-215-X 
mes $^{87}$, el cual vino a Castilla después de 1080 y allí permaneció hasta su muerte en 1097. Pese a todo, decidir si se trata de una reina u otra es una cuestión que carece aquí de interés. Lo que persigue don Rodrigo parece más bien resaltar el influjo que ejercieron sobre el monarca castellano-leonés el hecho de tener esposas extrajeras, procedentes de las Galias. En cierta manera, este factor funciona como atenuante de la responsabilidad del rey, dada la presión sutil y constante de su esposa.

Por otra parte, $R H$ exagera a todas luces la amplitud y el grado de intensidad de la oposición surgida contra la supresión de la liturgia autóctona. De hecho, este texto ha servido a Mansilla para mostrar el ambiente de lucha, tensión y división existente en Castilla por causa de la cuestión litúrgica ${ }^{88}$. Fijémonos en las alusiones concretas que aparecen en el capítulo 25:

- clerus et populus tocius Hispanie turbabatur, eo quod Gallicanum officium suscipere a legato et principe cogebantur;

- fuit diucius altercatum, clero, milicia et populo firmiter resistentibus ne officium mutaretur;

- Ad hoc ultimo res peruenit militari pertinacia decernente, ut hec dissensio duelli certamine sedaretur;

- Et tunc cunctis flentibus et dolentibus prouerbium inoleuit: "Quo uolunt reges uadunt leges».

De acuerdo con el Toledano, quienes se oponen al cambio son todos los estamentos sociales, a saber, el clero, el ejército y el pueblo. Además, el ámbito de la reacción social abarca a toda España, lo que equivale a decir a todo el reino, adquiriendo una enorme intensidad, reflejada en el prolongado altercado, en la obstinación de los soldados que lleva hasta la celebración del duelo y la ordalía, y finalmente en el dolor de todos ante la inalterable decisión del rey. Éste, pese a los fracasos de los juicios de Dios, aparece como implacable ejecutor de su voluntad, ordenando al fin el cambio en virtud de su potestad y bajo severas amenazas.

Por último, en nuestro relato se incorpora un elemento significativo desde el punto de vista histórico. Se trata de la pervivencia del rito hispano en algunos monasterios (in aliquibus monasteriis) y de la utilización de la traducción hispana del salterio en muchas catedrales y cenobios (in plurimis ecclesiis cathedralibus et monasteriis). Ciertamente, el monacato hispano dio muestras de una sólida adhesión a su tradición litúrgica. Tal fue el caso, por ejemplo, de San Millán de la Cogolla y, tal vez en menor grado, de Santo Domingo de Silos ${ }^{89}$. Por

87 J. J. RODRÍGUEZ Velasco, «Qué liturgia celebró san Lesmes al llegar a Burgos», en S. LÓPEZ SANTIDRIÁn (dir.), San Lesmes en su tiempo, Burgos, 1997, 239-241.

${ }^{88}$ Mansilla, «El reino de Castilla y el Papado...», 50.

89 Rubio SADIA, 60-62. 
ello, es muy probable que esta noticia de $R H$ proceda de fuentes próximas a los referidos monasterios. En cuanto a la traducción del salterio el ámbito de pervivencia abarca también a la catedrales. Fue bastante común que incluso después de adoptar el nuevo rito se continuara con la traducción latina hispana.

\section{BALANCE FINAL}

Las obras historiográficas compuestas en los siglos XII y XIII en los reinos de Castilla y León han recibido de forma desigual los acontecimientos relativos al cambio de liturgia de finales del siglo XI. Tenemos que reconocer que su información es escasa y, en cierta medida, tendenciosa o legendaria. A medida que nos alejamos de los hechos históricos las noticias se van orientando hacia aspectos legendarios incorporados por primera vez en la $C N$ y retomados por los cronicones y el Toledano en el siglo XIII. Pese a estos límites, comprobamos también que el corpus historiográfico estudiado proporciona algunos datos indispensables al historiador que se acerca al tema en cuestión. Los más importantes se encuentran en las obras del siglo XII, ya que en la centuria siguiente el cambio de rito pierde relevancia hasta llegar a $R H$, donde Jiménez de Rada lo retoma con plena libertad en vista a sus propios fines. De hecho, desde la $C N$ hasta $R H$, encontramos alusiones lacónicas y efímeras tanto en la $C S_{2}$ como en los cronicones, sin contar la inexistente alusión del $C M$ que ha dado pie a notorios equívocos.

Si bien el cambio de rito interesó tanto a la Corona castellano-leonesa como a Roma, la iniciativa se atribuye en principio únicamente a Alfonso VI, según lo que hemos convenido en llamar versión «oficial». Pero con el tiempo surgen otros factores que desplazan o atenúan este protagonismo del monarca. Tales son la autoridad romana, que podría traslucirse en el texto de $C S_{2}$, de acuerdo con la interpretación de Reilly, o la influencia de la reina francesa Constanza de Borgoña, continuamente presente en la narración de Jiménez de Rada.

La ciudad donde se comunicó por primera vez la decisión del rey sobre la supresión de la liturgia hispana fue sin lugar a dudas Burgos (así en la CP y la $C N$ ). La ciudad castellana fue escenario igualmente del fenómeno de oposición simbolizado por la celebración de juicios de Dios. La manipulación de $R H$, que sitúa en el Toledo reconquistado estos relatos, sólo se explica dentro de su programa de asegurar la primacía eclesiástica de Toledo en tiempos problemáticos.

Finalmente, las fechas claves que nos proporcionan los textos estudiados son tres. En primer lugar, 1076 es el año de la declaración del mandato real. Esta fecha es explícita en los cronistas más tempranos (la $C P$ y la $C S_{1}$ ). Pero no la contradicen ni la $C N$, ni los cronicones del siglo XIII. En 1076 Alfonso era el único rey peninsular en cuyos estados no se celebraba la liturgia romana. La

Hispania Sacra, Medievalia hispanica, 58

117, enero-junio 2006, 9-35, ISSN: 0018-215-X 
aparición de otra fecha se explica por la necesidad de sancionar de forma definitiva la orden de 1076 a raíz de las resistencias que bloquearon el cambio. Así, en el $C B$ se asigna el año 1078, vinculando el cambio a la primera legación del cardenal Ricardo. Por otra parte, ninguna de las fuentes menciona explícitamente el gran concilio de 1080 que conocemos gracias a otros documentos. La tercera fecha importante es 1077, año en el que se data la agitación social producida por la decisión del monarca y que recoge por vez primera la $C N$. Esta resistencia ha quedado simbolizada por el duelo y la ordalía celebrados en Burgos, que constituyen la narración más popular de la supresión del rito tradicional hispano hasta nuestros días. 